\title{
VER COM OS OLHOS DOS OUTROS: (DES) ENCONTROS E AFETOS EM INCURSÕES ETNOGRÁFICAS ${ }^{1}$
}

\author{
Carolina Branco de Castro Ferreira ${ }^{2}$
}

Recebido em: Novembro,2013 Aceito em: Dezembro, 2013

Para citar este artigo:

FERREIRA, Carolina; "Ver com os olhos dos outros: (des) encontros e afetos em incursões etnográficas.” In: Revista Intratextos, 2013, vol 5, no1, p.75-94. DOI: http://dx.doi.org/10.12957/intratextos.2013.11908

\footnotetext{
${ }^{1}$ Este artigo é uma adaptação de um dos capítulos de minha tese de doutorado Desejos Regulados: grupos de ajuda mútua, éticas afetivo-sexuais e produção de saberes, defendida no programa de pós-graduação em ciências sociais da Unicamp. A pesquisa foi realizada durante o período de 2008-2012 com financiamento integral do CNPQ.

${ }^{2}$ Doutora pelo Programa de Pós-Graduação em Ciências Sociais /UNICAMP. Pesquisadora colaboradora ligada ao Núcleo de Estudos de Gênero Pagu/UNICAMP. Pesquisa financiada pelo CNPQ/Brasil. carolinabcf.uni@gmail.com
} 
Se podes olhar, vê. Se podes ver, repara.

(José Saramago - Ensaio sobre a cegueira)

\section{Introdução}

No período de 2008 a 2011 realizei o campo etnográfico de minha pesquisa de doutorado, que dentre outras questões, tratou da socialidade produzida entre grupos anônimos de ajuda mútua identificados com as noções de vício em sexo e/ou amor. Apesar de ter-me concentrado nos Dependentes de Amor e Sexo Anônimos (DASA), Mulheres que Amam Demais Anônimas (MADA) e Co-dependentes Anônimos (CODA) na cidade de São Paulo, o trabalho etnográfico envolveu diversos outros grupos, tais como Devedores interesse explicativo e teórico, no sentido de sistematização de conhecimento e de produção de teorias nativas, de alguns grupos mais do que outros, mas os significados e sentidos circulavam Anônimos, Neuróticos Anônimos, Alcoólicos Anônimos GLS $S^{3}$, e etc. Isso porque, neste contexto, frequentadores/as de diferentes grupos usavam as mesmas noções, tais como fundo do poço, codependência, anorexias, e descobri que algumas delas eram objeto de em vários deles. Deste modo, percebi que os grupos formavam fluxos pelos quais circulavam sujeitos e significados, bem como eram produtores de uma socialidade bastante particular.

Essa descoberta etnográfica fez com que eu não caísse numa espécie de "conto do grupo", ou seja, não os encarassem como entidades discretas produtoras de coerências permanentes. Seguir os fluxos entre os grupos e a circulação de sujeitos por eles, permitiu pensar a emergência de uma gestão coletiva de mal-estares sociais ligados à produção de convenções afetivo-eróticas que operavam por meio de redes sociais heterogêneas. Em um contexto no qual a articulação entre privacidade/interioridade das emoções e a emergência de noções de espaço público, nos quais a linguagem do testemunho pessoal e do sofrimento

${ }^{3}$ A sigla GLS refere-se a "gays, lésbicas e simpatizantes". 
serviam de mediadores simbólicos entre a experiência subjetiva, a generalização social e gestões e implicações no âmbito de políticas sexuais e de conhecimentos especialistas ${ }^{4}$.

Ao longo do estudo, para contemplar a heterogeneidade que aparecia no material coletado, também fiz incursões etnográficas no Instituto de Psiquiatria do Hospital das Clínicas de São Paulo que mantém um ambulatório para sexo compulsivo e amor e ciúmes patológico. $\mathrm{O}$ recurso teórico-metodológico de triangular imperativos e saberes médicos articulados a demandas e experiências individuais e ansiedades culturais no sentido do apelo popular e leigo destes temas (Irvine, 2005), permitiu entender a importância de elementos leigos na constituição de saberes e na estruturação de serviços médicos/especialistas 5 .

Neste trabalho busco refletir sobre minha experiência ao longo do campo etnográfico a partir dos afetos presentes ao longo das negociações com diferentes sujeitos ao longo da pesquisa. Além disso, tal exercício reflexivo e minha trajetória pelos âmbitos que constituíram o estudo são privilegiados para compreender a sobreposição de aspectos na (co) produção de elementos leigos e especialistas, bem como de autoridades sociais ligadas a emergência das noções de vício em sexo e/ou amor.

\section{ANTROPÓLOGA, COMPANHEIRA E MAIS ALGUMA COISA: TENSÕES E PROBLEMATIZAÇÕES DO CAMPO ETNOGRÁFICO}

Como se vê, quando um etnógrafo aceita ser afetado, isso não implica identificar-se com o ponto de vista do nativo, nem aproveitar-se da experiência do campo para exercitar seu narcisismo. Aceitar ser afetado supõe, todavia, que se assuma o risco de ver seu projeto de conhecimento se desfazer. Pois se o projeto de conhecimento for onipresente, não acontece nada. Mas se acontece alguma coisa e se o projeto de conhecimento não se perde em meio a uma aventura, então uma etnografia é possível. (FAVRET-SAADA, 2005)

Os encontros semanais dos grupos seguem um padrão e operam a partir de uma série de práticas ritualizadas. A condição básica para ser membro é de natureza existencial e a filiação aos mesmos se dá por auto identificação. Nenhuma verificação é feita, sendo

\footnotetext{
${ }^{4}$ Ver mais sobre o tema em Ferreira, 2012.

${ }^{5}$ Ver Ferreira (2013)
} 
levada em consideração somente a auto declaração do sujeito o que, por sua vez, lhe permite trocar, sair e/ou entrar no grupo quando quiser. Sendo assim, o que legitima a participação é a experiência dos sujeitos, entendida como um lugar da veracidade e de motivação emocional para o engajamento nas práticas coletivas.

Embora o surgimento e a produção do conhecimento antropológico estejam historicamente ligados ao estudo das "outras sociedades", a cidade, a metrópole, o espaço urbano e suas relações já se consolidaram como objetos de estudo privilegiados no âmbito da disciplina 6 . Nesse sentido, muitos/as antropólogos/as têm feito suas pesquisas prioritariamente no espaço urbano, ou seja, na maioria das vezes, em sua própria sociedade $^{7}$. As reflexões metodológicas sobre o trabalho de campo, sua característica reflexiva, sua regulamentação, suas relações de poder e os posicionamentos que o antropólogo deve ou não adotar ao fazer pesquisa etnográfica em sua sociedade e em outras, tem sido objeto de reflexões éticas e problematizações de naturezas diversas.

Sabe-se que, quando o antropólogo vai a campo, não é apenas ele quem procura familiarizar-se com o universo cultural do grupo no qual se insere, pois este também mobiliza seu sistema de classificação para tornar aquele que inicialmente era um “estrangeiro" em uma "pessoa de dentro", isto é, um sujeito socialmente reconhecido. Isso é comum nas sociedades indígenas, por exemplo, nas quais, muitas vezes, o antropólogo recebe um "nome nativo" e é classificado nas categorias de gênero, idade, estado civil e parentesco (SILVA, 2000). As formas de inserção e iniciação variam de acordo com os grupos pesquisados.

\footnotetext{
6 Por exemplo, no século XIX, Simmel (1979) tinha na metrópole e nas relações sociais que ela criara símbolos fundamentais das condições de aparecimento de sua ideia de modernidade. Outro autor contemporâneo a ele é Park (1979), um dos representantes da Escola de Chicago nos Estados Unidos no começo do século XX, que propunha novos métodos para o estudo das cidades, pois as considerava um grande laboratório do comportamento coletivo.

${ }^{7}$ Ver a reflexão de DaMatta (1978) sobre as maneiras para transformar "o exótico em familiar e o familiar em exótico", ou ainda, o comentário de Velho (1981, p.126): "o que sempre vemos e encontramos pode ser familiar mas não é necessariamente conhecido e o que não vemos e encontramos pode ser exótico mas, até certo ponto, conhecido (...) estamos sempre pressupondo familiaridades e exotismos como fontes de conhecimento ou desconhecimento, respectivamente"
} 
Por vezes, os primeiros contatos com os grupos foram tensos, pois, após minha apresentação como pesquisadora, muitos/as participantes não concordavam com minha permanência na sala. Nesse primeiro momento, minha presença nas reuniões era sempre votada e às vezes objeto de especulações, curiosidades e conflito:

Na primeira vez no DASA, na reunião da igreja no bairro de Santa Cecília, região central da cidade de São Paulo, encontrei Janaína na sala. Ela é uma mulher grande, "branca", bochechas rosadas, cabelos compridos, lisos e castanhos. Faltavam 15 minutos para a reunião começar, perguntei se o encontro de DASA seria ali e se ela seria a facilitadora. Janaína respondeu afirmativamente as duas perguntas. Enquanto conversávamos ela preparava a mesa para a reunião e os utensílios para o cafezinho que é servido no intervalo. Expliquei minha situação, disse que gostaria de frequentar as reuniões por conta da minha pesquisa e que já participava do MADA e do CODA. Janaína olhou calmamente e disse que por ela tudo bem, mas teria que perguntar para a "consciência coletiva" do grupo. Homens e mulheres chegaram e quando havia cerca de 20 pessoas na sala, Janaína expôs meu pedido de estar presente na reunião como pesquisadora. Eu tive a oportunidade de falar um pouco da pesquisa. No entanto, a votação foi feita e o grupo não permitiu que eu ficasse. Eu tentei argumentar e fui interrompida por um rapaz negro, de aproximadamente 27 anos : "Se você quiser saber sobre o grupo, por favor, acesse o nosso site. Agora, por favor, nos dê licença, pois já estamos atrasados" e fez um gesto com a mão em direção à porta. Eu disse: "Tudo bem, já estou indo". Quando eu estava no meio do corredor, ouvi alguém me chamar: "Ei moça!!" Virei e era um dos rapazes que estava na sala. Ele me fez várias perguntas sobre a pesquisa e disse que naquele grupo "havia muita gente com pouca visão". Segundo ele, não haveria nenhum problema em minha pesquisa, e caso o grupo aceitasse minha participação estariam praticando o $12^{\circ}$ passo. Eu perguntei o nome do rapaz com o qual conversava: "Você pode me chamar de Luiz Américo, mas este não é o meu nome verdadeiro". Nós caminhamos até a saída da igreja e paramos em frente a uma banca de jornal para que eu pudesse pegar um papel para anotar seu telefone. Logo que o consegui, ele disse: "Vamos sair aqui da frente, eu não posso ficar perto de bancas de jornal, você sabe por que, né?" Eu respondi: "Não, eu não tenho ideia”. Luiz Américo explicou que era por conta de seu vício por revistas, vídeos pornográficos e masturbação. Nossa conversa terminou com ele dizendo: "Olha, eu gostei de você e acho que a sua pesquisa é séria. Eu coordenarei a reunião do sábado lá no Itaim. Vamos combinar de você ir lá, porque como vou ser eu quem vai estar na mesa, vou colocar a sua questão e ela terá mais chances de passar”. (Notas de campo, São Paulo, Janeiro 2008)

Nas negociações de minhas inserções, aprendi a lançar mão do argumento de ser doutoranda da Unicamp, da pesquisa ter quatro anos de duração e da insistência em 
presenciar as reuniões para garantir a convivência necessária pelo tipo de metodologia utilizada por mim. Isso garantia alguma legitimidade diante das pessoas que frequentavam os encontros. Neste momento, apesar da minha identidade altamente marcada como antropóloga, podia negociar um lugar, ainda que de separação/afastamento naquele universo.

Nas práticas ritualizadas de ajuda mútua no formato dos 12 passos e 12 tradições $^{8}$, há sempre um momento para os que estão ali pela primeira vez se apresentarem, contarem como conheceram o grupo e serem convidados a participar das reuniões ${ }^{9}$ como membro. Neste momento, é dito várias vezes que os que estão ali pela primeira vez são as pessoas mais importantes da ocasião e que elas não estão mais sozinhas. Os novatos ganham um kit de ingresso ou lembrancinha ${ }^{10}$, contendo folhetos informativos que trazem os endereços do grupo na cidade, os dias e horários dos encontros, perguntas de auto-diagnóstico ${ }^{11}$, dicas terapêuticas, textos explicativos com as principais noções da irmandade, os 12 passos, as 12 tradições, a oração da serenidade ${ }^{12}$ e, às vezes, um breve histórico do grupo.

No inicio do trabalho de campo, embora algumas vezes tivesse oportunidade de falar de minha pesquisa no começo da reunião para que os participantes votassem minha presença, todas as primeiras vezes em um grupo fui recebida como potencial companheira, pois chegada a $3^{o}$ tradição $o^{13}$, como é chamado o momento de ingresso dos visitantes ou

\footnotetext{
${ }^{8}$ Os 12 passos e 12 tradições são um conjunto de códigos prescritivos que organizam os grupos anônimos de ajuda mútua e também as condutas dos sujeitos.

${ }^{9}$ Reunião (e seu plural) aparece em itálico porque se refere ao modo nativo como os/as frequentadores/as definem os encontros semanais, também é comum o uso de salas.

${ }^{10}$ No MADA esses folhetos são chamados de lembrancinhas, no DASA e demais grupos são chamados de kit de ingresso.

${ }^{11} \mathrm{O}$ autodiagnostico é um conjunto-guia de perguntas para que os sujeitos avaliem a partir de sua conduta a pertinência de seu autoconsiderarem como viciados em sexo e ou amor. Este item é bastante relevante no conjunto de elementos que compõe os fluxos entre os grupos, bem como são protagonistas na coprodução entre estes e imperativos médicos/psi e a cultura textual da autoajuda, por meio da qual os sujeitos constituem-se como pessoas e negociam os supostos danos, sentidos e significados de suas várias dependências.(Ver Ferreira, 2012.)

12 Dentre as práticas que encarnam ao mesmo tempo a natureza do rito e da crença (Mauss, 1979) está a oração da serenidade que inicia e finaliza qualquer encontro no âmbito dos grupos.

13 Nesta tradição está estabelecido que o único requisito para ser membro de qualquer grupo de ajuda mútua anônimo é o desejo de parar de viver em padrão de dependência seja ele qual for (amor, sexo, afeto, álcool, drogas e outros).
} 
iniciantes, eu era convidada a apresentar-me, falar de mim caso quisesse ${ }^{14}$ e também ganhava os folhetos.

Com a frequência nos encontros semanais, apesar de não compartilhar pessoalmente uma "verdade" do grupo, por exemplo, num primeiro momento não partilhava" nas reuniões. No entanto, eu participava de suas etiquetas e do seu sentido de unidade. Ao participar do rito de diversas formas, lendo trechos da literatura $^{16}$ quando solicitado, fazendo a oração da serenidade em conjunto com eles/elas etc., a visão sobre mim começou a ser matizada e o meu lugar de antropóloga passou a ser menos marcado.

A partir daí, passei a ouvir em diferentes grupos e de diversas pessoas: "E ai??" "Vai entrar para o grupo ou vai só ficar na pesquisa?" Além disso, as pessoas passaram a dirigir-se a mim pela categoria nativa de companheira em diversos momentos. As suspeitas levantadas nas primeiras vezes de que eu seria uma jornalista foram afastadas e eu comecei a ganhar "aliados" para minha permanência nas salas:

14 Nas primeiras vezes eu aproveitei esses momentos para falar de minha pesquisa e explicar sobre a importância da não identificação pessoal dos sujeitos durante o estudo.

${ }^{15}$ A partilha é uma categoria êmica que significa compartilhar sua experiência com os outros. Toda vez que um sujeito toma a palavra, ou é sua vez de dar seu depoimento no grupo, ele/a publiciza sua aflição relativa a um suposto sofrimento ou descontrole emocional, afetivo ou sexual. Segundo o princípio da ajuda mútua anônima, esta prática funciona como um espelho para a recuperação dos outros participantes. A partilha ou depoimento podem acontecer no grupo, em conversas on-line, estarem publicadas em materiais impressos ou, ainda, estarem disponibilizadas nos sites dos grupos. Neste sentido, as partilhas possibilitam colocar o eu como um objeto de investigação de maneira que o converta em uma representação pública. Essa dinâmica permite organizar a experiência social, negociar a distância entre o eu e os outros e traçar os limites do eu privado e público. Os temas das partilhas são diversos: todo tipo de consumo no mercado sexual, desentendimentos familiares, brigas e separações conjugais, infidelidade, ciúmes, homossexualidade, desejos (homo)eróticos diversos (por exemplo, por pés, por menores de idade, por pessoas de classes sociais distintas, por vestir-se com roupas do sexo oposto (praticada relatada sempre por homens), praticar atos sexuais considerados perigosos e em lugares supostamente inapropriados (ter relações sexuais sem preservativo, transar em lugares públicos ou ainda nos quais corre-se o risco de ser assaltado ou surpreendido por alguém), violência doméstica (tanto mulheres relatando sofrerem maus tratos físicos de seus companheiros e não conseguirem deixá-los, quanto homens falando com arrependimento de situações nas quais usaram a força física com suas parceiras), busca por relações afetivo-sexuais, etc. As partilhas revelam dimensões da interioridade veiculadas por ideias como vazio interior e noções de movimento como alta e baixa estima no preenchimento de tal vazio. Estas noções também podem ser expressas corporalmente, por exemplo, quando as pessoas partilham, colocam a mão sobre a região peitoral indicando seu interior que deve ser descoberto.

${ }^{16}$ Literatura são os livros de auto-ajuda e o material produzido pelos próprios grupos com a finalidade de oferecer subsídios de leitura (noções e categorias) para os sujeitos se identificarem como membros do grupo e, a partir daí, re-significarem seus sofrimentos e, de modo geral, a narrativa sobre a própria vida. 
(...) Somadas às conversas agradáveis que temos, Luiz Américo revelou-se um aliado para minha inserção nas reuniões do DASA. Como combinado, fui à reunião do grupo na igreja do Itaim no sábado, pois seria ele o facilitador naquele dia. Cheguei mais cedo e aguardei sua chegada. Ele apareceu com outras pessoas e rapidamente veio até mim: "Olha, Carol, acho que não vai rolar. Eu vim com o pessoal no ônibus e inseri a ideia de você participar e eles não concordaram. Mas, a gente faz assim: eu te apresento como uma amiga que veio conhecer o DASA e você começa a participar". Naquele momento passou pela minha cabeça todos os textos e discussões sobre ética na antropologia e rapidamente eu respondi: "Não, Luiz”. "Eu não posso fazer isso. Porque em algum momento todos irão descobrir que sou antropóloga e não confiarão mais em mim, esse não tem sido o modo que tenho frequentado as reuniões". Conversamos mais um pouco. Ele argumentou que eu não estava fazendo nada de errado, pois as reuniões eram abertas para quem quisesse frequentar. Eu tentei explicar mais uma vez os meus motivos, mas Luiz me convenceu a entrar na sala e lá resolveríamos a questão. No caminho da porta da igreja até o lugar onde acontecem as reuniões, lembrei do filme "Clube da Luta" e do personagem sem nome de Edward Norton que, para apaziguar sua angústia e insônia, frequentava reuniões de anônimos fingindo ser um deles. Eu estaria prestes a me tornar uma farsante? $O$ que eu teria em comum com aquela personagem? Em nome de uma pesquisa, eu estaria em busca de resolver dramas pessoais? Não sei, respondi para mim. No entanto, aquela situação não era ficção, muito menos filme. Luiz Américo e eu sentamos um ao lado do outro na sala, enquanto outras pessoas arrumavam a mesa para a reunião. A facilitadora daquele dia era Marcela, que questionou Luiz: "Essa é a antropóloga de quem você falou?” Ele respondeu: "Não! Ela é uma amiga que veio conhecer a reunião". Eu interrompi e repeti minha ladainha de sempre: "Sim! Sou a antropóloga e gostaria de participar de algumas reuniões, tenho uma pesquisa de doutorado pela Unicamp sobre grupos anônimos relacionados ao amor e sexo. Há quase dois anos tenho frequentado o MADA e o CODA e gostaria de começar aqui no DASA". Houve um longo debate sobre a minha participação no qual as pessoas se inscreviam para falar, inclusive eu. Naquele dia, no debate sobre a minha participação ou não no DASA, deixei claro que eu não era jornalista, certamente o anonimato seria respeitado, e que a característica de minha pesquisa demandava tempo e qualidade na relação com as pessoas no grupo. Depois de muita discussão e argumentos contra e a favor da minha estada ali, ela foi aceita pela "consciência coletiva". Minha participação foi votada muitas outras vezes neste e em outros grupos, embora nas outras tenha sido menos tenso e os próprios/as participantes tenham saído em minha defesa. Em outra votação sobre minha participação no DASA, Luiz Américo tomou a palavra no grupo e disse que, numa de suas recaídas em procurar pornografia na internet, havia achado um texto de minha autoria; votou positivamente para minha permanência na reunião ao afirmar que meu trabalho era muito importante para o grupo (Notas de campo, São Paulo, Janeiro de 2008). 
De modo geral, todas as vezes que me apresentei como pesquisadora nos grupos, as pessoas demonstravam preocupação sobre o anonimato delas, e perguntavam se em minha pesquisa, ele seria garantido e se o trabalho seria publicado em jornal/revista ou transmitida pela TV. Os grupos anônimos têm uma política especial de comunicação com a mídia, principalmente os relacionados ao amor/sexo e descontrole emocional, com a finalidade de criar uma "gestão das informações que os sujeitos dão de si" (Frois, 2007) para não estigmatizar os frequentadores.

Pouco a pouco minha permanência passou a não ser mais votada e os/as participantes, ao invés de indagarem sobre as conclusões da pesquisa, começaram a me contar suas histórias. Frequentemente, passei a ser convidada para sair depois dos encontros, a conhecer outros grupos e, como consequência, estreitei laços de amizade com uma série de pessoas.

Com o passar do tempo cada vez mais minha presença e a pesquisa eram inseridas no contexto semântico e de etiquetas dos grupos. Minha relação com muitas pessoas era contextualizada a partir das práticas ditas terapêuticas. Assim, muitos/as entendiam que meu estudo poderia ser um meio de o grupo praticar a $12^{\circ}$ passo $^{17}$. Além disso, vários deles/as encaravam o processo de entrevista como uma partilha, como um meio de praticar a recuperação e o $5^{\circ}$ passo ${ }^{18}$.

Durante o processo de entrevistas e com a continuidade de minha presença nas reuniões, meu silêncio nas partilhas passou a ser indagado. Além disso, eu não sabia responder aos meus colaboradores quando era questionada sobre qual era o meu problema, mas nas conversas que mantínhamos e quando relatava algum fato de minha vida pessoal,

\footnotetext{
${ }^{17}$ Este passo está relacionado a publicização do grupo a partir do julgamento de que outras pessoas também compartilham sofrimentos similares: Tendo experimentado um despertar espiritual, graças a esses passos, procuramos transmitir esta mensagem aos dependentes de amor e sexo e praticar estes princípios em todas as áreas de nossas vidas. (Fonte: Folhetos informativos e http://www.slaa.org.br/br/index.htm).

${ }^{18} \mathrm{O} 5^{\circ}$ passo é ligado à prática de produção de um inventário moral por meio da biografia pessoal no qual os sujeitos pontuam, descrevem e reconhecem vivências e traços pessoais que passam a estar ligados ao vício de sexo/e ou amor. Eles/as exercitam tal prática conversando com outros participantes ou através da escrita: Admitimos perante Deus, perante nós mesmos e perante outro ser humano, a natureza exata de nossas falhas. (Fonte: Folhetos informativos e http://www.slaa.org.br/br/index.htm).
} 
esse era imediatamente classificado dentro do repertório do grupo. Assim, embora durante todo o tempo de pesquisa eu não tenha me considerado uma adicta em sexo ou em amor, as pessoas se relacionavam comigo como tal.

A natureza da minha relação com os participantes me fazia pensar se, por ter ficado tanto tempo em campo, assistido a tantas reuniões, conversado inúmeras vezes com aquelas pessoas, ter passado significativas horas dos meus finais de semanas com elas/es e o mais importante, ter aceito o lugar de companheira e os afetos que abriram uma comunicação específica, ou seja, uma comunicação involuntária e desprovida de intencionalidade, que podia ser verbal ou não (FAVRET-SAADA, 2005), passei a contar a minha história pessoal, mesmo sem me dar conta, através da musicalidade que atravessava as narrativas dos/as frequentadores/as dos grupos.

Neste sentido, além de "emprestarem seus olhos"19 para que eu pudesse entender determinadas questões a partir de certa perspectiva, as pessoas com as quais eu convivia durante o trabalho de campo estavam me convidando a experimentar pessoalmente, a partir de minha própria narrativa, os efeitos reais da rede particular de comunicação que se estabelecia através da socialidade criada. Então passei a entender os pedidos para que eu partilhasse, pois diziam que minha história pessoal era importante para o grupo. Isso fazia com que eu entrasse como parceira e que nessa relação investisse os problemas e sofrimentos de minha existência desde então.

Nas reuniões, além de as narrativas tratarem dos sofrimentos a partir das categorias e noções específicas produzidas pelos grupos, de modo geral, elas trazem à cena questões e aborrecimentos do cotidiano, ou seja, da ordem do ordinário. Então, algumas vezes partilhei e depois de um tempo durante uma reunião de serviço ${ }^{20}$ no grupo DASA do Santa Cecília, fui convidada (no entanto, soou quase como uma obrigação tendo em vista o tempo de

\footnotetext{
${ }^{19}$ Comentário de Adriana Viana sobre trabalho de campo no Seminário Convenções de Gênero, Sexualidade e Violência, realizado pelo Núcleo de Estudos de Gênero - PAGU/UNICAMP, em Campinas/junho de 2011.

${ }^{20}$ Elas acontecem, geralmente, uma vez por mês durante os encontros semanais. As reuniões de serviço têm como finalidade criar espaços nos quais são debatidos e decididos aspectos organizacionais de cada grupo.
} 
minha participação na sala) a ser primeira secretária ${ }^{21}$. Neste contexto, durante três meses passei a ter as chaves do local e a obrigação de abri-lo para os encontros, bem como fui facilitadora de algumas reuniões.

Não é minha intenção mostrar como "me tornei nativa", até porque não acredito que isso seja possível. Embora tenha permitido "ser afetada" (FAVRET-SAAD, 2005) pelas relações às quais era convidada a entrar, jamais abdiquei a não compreendê-las. Assim, olhando minhas notas e escolhas metodológicas e etnográficas, é como se tivesse feito de minha "participação" um instrumento de conhecimento (idem, 2005), uma vez que o conhecimento antropológico é prontamente uma relação social e o resultado das relações que constituem ao mesmo tempo "o sujeito que conhece e o sujeito que ele conhece". Além disso, esse conhecimento é o agente de uma transformação na constituição relacional de ambos (VIVEIROS DE CASTRO, 2002a) e, segundo minha experiência na constituição da própria pesquisa.

Outro aspecto do trabalho de campo foi como o Consentimento Informado de Participação na Pesquisa entrou no contexto deste estudo. No âmbito nacional e internacional, as associações e organizações ligadas à Antropologia têm sido muito críticas quanto à conveniência e importância legitimadora deste instrumento para a pesquisa antropológica, inclusive optando por não usá-lo em muitos contextos etnográficos.

Vários autores já se pronunciaram a propósito das polêmicas existentes na visão atual sobre ética nas pesquisas, apontando a tônica do biocentrismo e as dificuldades epistemológicas e práticas implicadas no uso deste instrumento como legitimador do processo de campo etnográfico. Oliveira (2004) faz uma distinção entre pesquisas em seres humanos e pesquisas com seres humanos Para ele, no primeiro caso, a relação é caracterizada como uma situação de intervenção, na qual seres humanos são colocados na situação de cobaias; neste tipo de pesquisa o consentimento informado constitui uma

\footnotetext{
${ }^{21} \mathrm{O} / \mathrm{a}$ primeiro/a secretário/a é um cargo temporário e não remunerado dentro do princípio dos serviços para a recuperação. Basicamente, consiste na responsabilidade de abrir a sala semanalmente, facilitar as reuniões de serviço e os encontros semanais, caso nenhum outro participante se disponibilize. Durante o período que estive à frente de tal posição, percebi que era parte da etiqueta oferecer aos presentes com mais de três meses de participação do grupo a coordenação da reunião.
} 
exigência não só legítima, mas da maior importância. No segundo caso, o sujeito da pesquisa deixa a condição de cobaia (objeto de intervenção) para assumir o papel de ator (sujeito de interlocução).

Neste sentido, em muitas situações de campo etnográfico o consentimento de pesquisa é desnecessário, porque intimida e até descaracteriza os sujeitos da pesquisa. Além disso, até as formulações mais detalhadas e com regras formalizadas sobre este assunto são incapazes de envolver todas as escolhas individuais e as questões de conduta ética numa pesquisa. Assim, pelo fato de antropólogos/as estarem submetidos, na maioria das vezes, a mais de um código de ética, a regulação referente ao consentimento passa pela qualidade dele, e não necessariamente por sua forma, no caso a necessidade do consentimento por escrito (American Anthropological Association, 1971) ${ }^{22}$.

Outro aspecto desse lugar de companheira era um constrangimento, na maioria das vezes de minha parte, em pedir entrevistas. A dinâmica do campo etnográfico demandou algum tempo até eu conhecer os grupos e achar conveniente solicitar gravar as narrativas e, durante este tempo, tive a impressão de que meu lugar de antropóloga praticamente se apagara de nossas relações.

Embora o contexto de meu estudo etnográfico não exigisse a necessidade de um consentimento informado de pesquisa, resolvi criar um, pois a formalidade que ele produz momentaneamente na relação abria um espaço de negociação referente à entrevista, inclusive para que os sujeitos não aceitassem concedê-la. Isso aconteceu três vezes com participantes homens; eles pediram para pensar, durante um tempo, se dariam ou não a entrevista e depois disseram que preferiam ficar somente como companheiros de grupo mesmo. Ainda, percebia que para algumas pessoas não havia problema nenhum em gravar suas narrativas, desde que houvesse um sigilo quanto seu nome e ocupação, pois para muitos/as deles/as a principal preocupação se dava no meio profissional. Além disso, a

\footnotetext{
${ }^{22}$ Disponível em Statements on Ethics: http://www.aaanet.org/stmts/ethstmnt.htm. Para debates contemporâneos sobre a atuação do antropólogo/a em diversos campos e suas implicações ver a coleção organizada pela Associação Brasileira de Antropologia (ABA) VÍCTORA, C. et al. (2004); Bonetti e Fleischer, (2007), Feriani et al. (2011), dentre outros.
} 
pesquisa também passou a envolver profissionais da área da saúde e neste meio o consentimento é praticamente indispensável ${ }^{23}$.

\section{O TRABALHO DE CAMPO NO AMBULATÓRIO INTEGRADO DE TRANSTORNOS DO IMPULSO (AMITI)}

O Instituto de Psiquiatria do Hospital das Clínicas da Faculdade de Medicina da Universidade de São Paulo (IPq-HCFMUSP), no qual está localizado o AMITI, atende usuários/as do Sistema Único de Saúde (SUS) encaminhados/as pelas unidades e serviços de saúde municipais e estaduais; também oferece atendimento a partir dos diferentes projetos de pesquisa ligados ao Departamento de Psiquiatria da instituição os quais envolvem aluno/as de graduação, residência e pós-graduação em psiquiatria, além dos/as discentes envolvidos/as em especializações e estágios para profissionais ligados à área de saúde mental. Ainda, o serviço também pode ser acessado por convênios particulares.

Durante três meses, às quintas-feiras, e eventualmente às quartas, estive pela manhã e parte da tarde no AMITI. Estes eram os dias em que as equipes do ambulatório de amor e ciúmes patológico e sexo compulsivo reuniam-se. Além destas duas especialidades, o ambulatório é constituído pela pesquisa e atendimento clínico estruturado para bulimia nervosa, cleptomania, compras compulsivas, dependência de internet, tricotilomania e automutilação. As equipes são constituídas separadamente pelos segmentos mencionados e contam com profissionais ligados ao Hospital das Clínicas e com alunos/as ligados/as à pós-graduação em psiquiatria e áreas referentes ao âmbito da saúde mental da USP. De modo geral, as equipes estão articuladas e há circulação de profissionais entre as

\footnotetext{
${ }^{23}$ Por exemplo, no Brasil, em 1996 a Comissão de Ética em Pesquisa (CONEP), órgão ligado ao Ministério da Saúde, decidiu pela resolução 196 que considera fundamental o uso do "Consentimento livre e esclarecido de participação na pesquisa". Este tema tem sido alvo de diversas polêmicas que envolvem as áreas de saúde e ciências humanas, principalmente porque a exigência das primeiras frequentemente inviabiliza o trabalho etnográfico. Para uma discussão bastante atual, na qual envolve cientistas sociais e associações profissionais ver: Antropólogos se retiram do Comitê de Ética em Pesquisa envolvendo seres humanos da UEL. Blog de História, Ciências, Saúde - Manguinhos. [viewed 14 May 2014]. Available from: http://www.revistahcsm.coc.fiocruz.br/antropologos-se-retiram-do-comite-de-etica-em-pesquisa-envolvendoseres-humanos-da-uel/
} 
especialidades do ambulatório. Além do AMITI, também entrei em contato com outros ambulatórios e programas do hospital relacionados à sexualidade e gênero, como o Ambulatório de Transtorno de Identidade de Gênero e Orientação Sexual (AMTIGOS) e o Programa Sexualidade (Pró-Sex). ${ }^{24}$

De modo geral, a permanência em hospitais para trabalhos etnográficos exige uma série de autorizações e burocracias, e meu interesse não era tanto os/as pacientes do AMITI, embora tenha conhecido alguns e participado de atividades voltadas para eles/as, mas sim nos profissionais. Minha ideia era levantar, a partir da trajetória profissional deles/as e da atuação no AMITI, uma parte da emergência do campo de uma medicina da adicção e sua articulação com o que poderíamos denominar de "sexologia cientifica" (IRVINE, 2005) e ou "nova sexologia" no Brasil (Russo et al, 2011), particularmente em São Paulo.

O trabalho de campo no hospital se deu num ambiente "hipercientífico". O valor da pesquisa como instrumento produtor de conhecimento é fundamental tanto na fala dos profissionais como na apresentação dos ambulatórios ${ }^{25}$. A noção de interdisciplinaridade também é relevante no modo como estes serviços são organizados e na maneira pela qual os/as profissionais pensam seu trabalho.

Neste contexto, quando me apresentei como antropóloga e doutoranda pela Unicamp, fui prontamente recebida e a maioria dos/as profissionais os quais procurava se mostrou receptivo a conversar e a responder às minhas perguntas. De certo modo, durante um tempo fui integrada como parte da equipe, pois li alguns trabalhos e dei informações sobre pesquisa qualitativa, propus uma disciplina sobre o tema, e escrevi, com mais dois

\footnotetext{
${ }^{24}$ Também durante as entrevistas com os frequentadores dos grupos e nas conversas com os profissionais do AMITI, foi citado o Programa de Orientação e Atendimento ao Dependente (PROAD) ligado ao departamento de Psiquiatria da Universidade Federal de São Paulo (UNIFESP). Segundo o site, este programa é destinado a dependências de substâncias ilícitas e lícitas, bem como atua na área de dependências não químicas como jogo patológico, sexo compulsivo, compradores patológicos e dependência de internet. http://www.proad.unifesp.br/-acesso em 23/10/2011.

25 Além do AMITI, do AMTIGOS e do PRÓ-SEX o Instituto de Psiquiatria do HC conta com aproximadamente 27 outros serviços dentre ambulatórios, programas e grupos de estudos que desenvolvem pesquisas. Conferir em: http://ipqhc.org.br/pag_detalhe.php?categ=Hospital\&id=241, acesso em: 19/11/2011
} 
psiquiatras, um pequeno texto de abertura para uma exposição fotográfica chamada “Cutting” realizada no Museu da Marinha em São Pauloº.

A ideia de companheira presente na primeira frente etnográfica parecia tomar outras formas na segunda, pois os afetos que a constituíam eram diferentes. Por exemplo, durante as entrevistas, quando eu apresentava o termo de consentimento e explicava sobre a pesquisa, muitos apenas "passavam os olhos", quando muito liam as condições do termo, numa atitude que misturava a credibilidade no meu estudo, mas também uma "praxe" com os instrumentos de pesquisa, como se aquilo representasse uma espécie de momento "burocratizado" necessário e previsível no script de encontros que envolvem pesquisas, produzindo reconhecimento de minha condição profissional ${ }^{27}$.

Assim, fiz algumas entrevistas nas intermediações do Hospital das Clínicas e outras no consultório particular dos/as entrevistados/as. Minha liberdade relativa de circular nos espaços do hospital e nos âmbitos de atuação dos profissionais permitiu compreender como a constituição do campo de saberes médicos e psicológicos sobre a adicção sexual e amorosa e as categorias a elas relacionadas neste contexto, articulavam dinâmicas especialistas-científicas, bem como eram fortemente influenciadas pela difusão, produção e incorporação pelo senso comum de tais noções, principalmente a partir de livros de autoajuda e da criação de grupos anônimos por sujeitos que passam a assumir tais identidades amorosas sexuais ${ }^{28}$.

Segundo a equipe do ambulatório de Amor e Ciúmes Patológico, os/as primeiros/as pacientes de tal serviço eram em sua maioria mulheres participantes do grupo de ajuda mútua MADA. De acordo com a psicóloga coordenadora, esse fato chamava a atenção da equipe e, num primeiro momento, durante as entrevistas de triagem no hospital era comum os/as profissionais perguntarem aos sujeitos sobre a participação em grupos anônimos.

\footnotetext{
${ }^{26}$ Texto disponível em: http://pt.scribd.com/doc/70131731/Os-Segredos-Do-Corpo

27 Apenas um profissional, preocupado com a veiculação correta de categorias e noções médicas, fez perguntas sobre como eu usaria a pesquisa e onde publicaria os resultados.

${ }^{28}$ Ver Ferreira (2013).
}

INTRATEXTOS, Rio de Janeiro, 5(1): 75-93, 2013. ISSN 2176-6789 
Neste contexto, os profissionais do ambulatório do amor e ciúmes patológico e o de sexo compulsivo pediram, devido a minha boa circulação entre os grupos, que eu divulgasse o ambulatório entre estes. Concordei em fazê-lo, pois mesmo diante da aceitação de minha presença no hospital, frequentemente havia conflitos entre os sujeitos referentes à minha participação nas triagens com os pacientes ou nas reuniões de supervisão da equipe.

Para a divulgação do ambulatório nos grupos elaboramos um cartaz o qual eu fixava nos locais onde as reuniões aconteciam. Além disso, quando tive oportunidade, falei sobre o serviço no espaço das reuniões do MADA e DASA reservado para recados. Muitos/as participantes se interessaram e perguntaram por maiores detalhes. Algum tempo depois, a coordenadora do ambulatório do amor e ciúmes patológico comentou que a divulgação havia dado certo, principalmente porque muitas mulheres participantes do MADA, por conta dos cartazes fixados nos locais nos quais ocorrem os grupos, haviam decidido procurar o serviço do hospital, pois avaliavam que somente o grupo era insuficiente.

Nas teorias nativas sobre a doença relacionadas ao vício em sexo e/ou amor presente nos grupos anônimos está presente a ideia de que a doença muda, a doença migra e, ao movimentar-se por diferentes zonas morais e físicas, mudam suas formas, práticas de manifestação e produz novos sujeitos. Neste contexto, a doença é um agente capaz de deixar rastros, enganar, ser sorrateira, silenciosa, migrar e transitar por várias formas de $\operatorname{associação~}^{29}$.

Interessante notar que esta concepção presente nos grupos, se traduz na emergência no campo especialista como um sujeito denominado impulsivo múltiplo. Em tal tradução, as dinâmicas presentes no campo médico e os modos de funcionamento dos serviços no hospital têm papel relevante, principalmente a forma e os elementos que os foram constituindo:

Aí, começou a chegar um tipo de encaminhamento engraçado. O mesmo discurso: "tô muito triste", "tô devendo", "pensei em tentar suicídio", ou "tentei suicídio", "as pessoas não me respeitam mais", "tô devendo pra todo mundo na rua”. Aí eu perguntava assim: Tá, qual o jogo? Qual é o que tá causando mais problema? "Não, não, eu não jogo". Mas, você não joga? "Não. É você que trata de gente impulsiva, que deve muito

${ }^{29}$ Conferir: Ferreira (2012)

INTRATEXTOS, Rio de Janeiro, 5(1): 75-93, 2013. ISSN 2176-6789 
dinheiro?". Sou. "Então, tô aqui pra falar com o senhor". Quem falou pra você falar comigo? "Ah, o Moacir". Ah, eu sempre brinco que é o critério Moacir. É a primeira vez. que a gente vai fazer um registro oficial disso. Moacir é um funcionário aqui da portaria do hospital, tá há anos aqui. Não aposenta porque vaso ruim não quebra. Há anos. $O$ Moacir é muito amigo meu, sou muito amigo do Moacir. Primeiro paciente assim, segundo paciente assim, e todos os problemas deles eram compras. Para ser inteiramente franco, alguns não eram via Moacir, mas a maioria veio via Moacir. Então os pacientes chegam, a portaria aqui é um grande centro de triagem informal. O cara chega aí da rua, com dois milhões de problemas, a primeira pessoa que eles desabafam é com o porteiro: "Meu, você não sabe o que tá acontecendo...". Ai o porteiro olha e pensa assim: "Você tem que falar com o [figura relevante, no caso o próprio entrevistado]". Quer dizer, você tá devendo, você gasta demais, você não tem juízo com dinheiro, vai falar com o. [figura relevante, no caso o próprio entrevistado]". Esse é o critério Moacir. Um ou outro paciente que não era jogador, que chegou assim: "Olha, meu amigo é jogador, ele falou que você é muito bom pra ajudar pessoas que tem esse tipo de problema"( de endividamento). Mas a maioria era o critério Moacir. Aí eu fui falar com o Moacir: O Moacir, que porcaria é essa? "Mas, doutor, o cara não gasta demais? Num fica desmoralizado? Não fica todo triste? Dizendo: $<<$ vou me matar, vou me matar $>>$ ? Então trata doutor. É tudo a mesma coisa” (...)ah, teve uma ótima, teve uma fantástica. Ligou uma mulher, que tinha problema com jogos, isso foi antes do Canadá ( local onde o entrevistado fez um pós-doutorado). Foram os germes que foram plantados. Quando voltei, pensei, preciso criar um espaço pra acolher essas pessoas. Ela ligou e falou assim, que tinha problemas com jogos e tal. Eu liguei, marquei, ela veio me contar a história, que ela...olha que a internet engatinhava naquela época. Você lembra de uns serviços que a Telesp tinha? Que você ligava e te colocava em contato com outras pessoas? Isso, que cruzava a linha com trinta, quarenta pessoas de uma vez? Ela ligava pra esses serviços e aí ela usava na verdade disso pra arranjar encontros sexuais. E depois ela ia pro motel com essas pessoas e tal, e numa semana ela tinha dez parceiros diferentes. Em um mês ela tinha tido quarenta parceiros diferentes. Bom, não era nem jogo nem compra. Mas, ela ligou aqui dizendo que tinha problema com jogo. Eu pareci um pouco contrariado, falei assim: Escuta, você falou que tinha problema com jogo. "Mas então, doutor, eu jogo o jogo do amor". Danada...gostei. No mínimo é inteligente, merece. "Explica que a gente vai te tratar". Ela tinha uma impulsividade implicada aí que eu falei: bom, um impulsivo com jogo, outro com compras, outro com sexo...tá na hora de conhecer essas coisas. Eu não botei esses caras pra fora. Eu fui acomodando eles ali, mas quando eu voltei do Canadá eu falei: tá na hora de levar isso a sério. Havia uma pressão que vinha da demanda social de pessoas com vários comportamentos excessivos, perda de controle sobre várias questões, e a gente não atendia bem. Aqui dentro, uma certa, de novo, questões políticas tal. Briga de cá, briga de lá. Pessoas contestando a minha autoridade, ou a minha capacidade pra liderar pesquisa, 
ensino e assistência nessas coisas. Eu falei assim: eu vou dar uma resposta a isso tudo. Eu vou montar um laboratório de impulsividade que não vai ter só jogo. Vai ter tudo o que envolver impulsividade (Médico Psiquiatra, São Paulo, 2011).

Ao recuperar a constituição dos serviços voltados para tratamento de compulsões e transtornos do impulso, principalmente aqueles voltados para temas que envolvem a sexualidade no $\mathrm{HC}$ em São Paulo, percebe-se como estes saberes foram fortemente influenciados pela articulação entre elementos e demandas leigas com o funcionamento do campo médico local.

Se tomarmos a criação de tais aparatos de verificação das verdades médicas como uma "cadeia de produção" é possível perceber que o funcionamento local deste campo não envolve apenas os "pares" (médicos e especialistas), mas também envolve a expertise, adquirida pela experiência de trabalho, pelo contato diário e intimo com a demanda que procura o hospital e facilitado por estar localizado simbólico-materialmente em outro lugar, de um sujeito considerado fora do âmbito profissional médico, como é o caso do "Moacir".

\section{Considerações Finais}

Ao longo do artigo, procurei refletir a partir dos afetos envolvidos em minha experiência etnográfica, a produção de verdades emocionadas como elementos operativos na produção de relatos e regimentos de si atuantes nos fluxos entre grupos anônimos de ajuda-mútua.

Ainda, por meio do recurso de minha inserção em campo mostrei como no processo local de constituição dos aparatos de verificação das verdades e dos enunciados que constituem o campo de saber sobre a compulsão do sexo e do amor e ciúmes patológicos, as demandas por tratamento psiquiátrico são produzidas pouco a pouco na intersecção entre as verdades emocionadas dos sujeitos e a busca por verdades racionalizadas no âmbito dos saberes psiquiátricos e médicos. Ainda que as verdades emocionadas e as racionalizadas façam parte de regimentos de si diferentes, elas não devem ser entendidas como entidades discretas e separadas. Neste contexto, ao se co- 
produzirem criam conhecimentos e comunicam-se a partir dos elementos que articulam emoções e moralidades no âmbito de sistemas de justificação.

\section{Referências Bibliográficas}

BONETTI, Alinne; FLEISCHER, Soraya (orgs.). Entre saias justas e jogos de cintura. Florianópolis: Editora Mulheres, 2007.

DA MATTA, Roberto. O ofício do etnólogo ou como ter Anthropological Blues . In: NUNES, Edson (org.). A Aventura Sociológica. Rio de Janeiro: Zahar, 1978.

FAVRET-SAADA, Jeanne. Ser afetado. Cadernos de Campo. São Paulo, ano 14, nº13, 155-161, 2005.

FERIANI, Daniela Moreno; CUNHA, Flávia Melo da; DULLEY, Iracema. Etnografia, Etnografias. São Paulo: Annablume Editora, 2011.

FERREIRA, Carolina Branco de Castro. Desejos Regulados: grupos de ajuda mútua, éticas afetivo-sexuais e produção de saberes. Tese de doutorado, Unicamp/IFCH, 2012.

FERREIRA, Carolina Branco de Castro. A emergência da addicção sexual, suas apropriações e as relações com a produção de campos profissionais. Sexualidad, Salud y Sociedad, no 14, 2013.

IRVINE. Janice. Desorders of Desire: Sexuality and Gender in Modern American Sexology. Philadelphia: Temple University Press, 2005.

MAUSS, Marcel. A prece. In: OLIVEIRA, Roberto Cardoso de. Mauss. São Paulo: Àtica. 1979.

OLIVEIRA, L Roberto Cardoso. Pesquisa em versus pesquisas com seres humanos. In: VÍCTORA, C. et al. (Org.). Antropologia e ética: o debate atual no Brasil. Niterói: Ed. da UFF, 2004.

PARK, Robert Ezra. A cidade: sugestões para a investigação do comportamento humano no meio urbano. In: VELHO, Otávio G. (org). O fenômeno urbano, Rio de Janeiro: Zahar, 1979.

RUSSO, Jane et al. Sexualidade, ciência e profissão no Brasil. Rio de Janeiro:Cepesc, 2011.

SILVA, Wagner. G. O antropólogo e sua magia. São Paulo: Edusp, 2000. 
SIMMEL, George. A metrópole e a vida mental. In: VELHO, Otávio G. (org.). $O$ Fenômeno Urbano, Rio de Janeiro, Zahar, 1979.

VELHO, Gilberto. Individualismo e cultura. Rio de Janeiro: Zahar, 1981.

VÍCTORA, Ceres. et al. (Org.). Antropologia e ética: o debate atual no Brasil. Niterói: Ed. da UFF, 2004. 